\section{Adsorption, Resorption, and Leaching of Oryzalin in Container Media and Soil}

\author{
Glenn R. Wehtje ${ }^{1}$, Charles H. Gilliam ${ }^{2}$, and Ben F. Hajek ${ }^{2}$ \\ Alabama Agricultural Experiment Station, Auburn University, AL 36849
}

Additional index words. herbicide, weed control, ornamental, environmental contamination
Irrigation runoff from landscape plant production areas and landscape developments could be a source of pesticide contamination for local water supplies or surrounding bodies of water (Keese et al., 1992). Wehtje et al. (1993) examined the adsorption, resorption, and mobility of ${ }^{14} \mathrm{C}$-labeled 3-[2,4-dichloro-5( 1 - methylethoxy)phenyl]-5-(1,1 dimethylethyl)-1,3,4-oxadiazol-2(3H)-one (oxadiazon) in three horticultural media and a mineral soil. Adsorption, which averaged $96 \%$, was influenced neither by the type of adsorbent (soilless media vs. soil) nor by oxadiazon concentration. However, resorption (i.e., release of adsorbed herbicide back into soil Oxadiazon displacement by leaching was mini$\mathrm{mal}$.

Published reports on the leachability of herbicides in container media have been reviewed (Wehtje et. al., 1993), but no similar studies have been conducted with 4(dipropylamino)-3,5-dinitrobenzenesulfonamide (oryzalin). Thus, our objective was to evaluate the adsorption, resorption, and mobility of oryzalin in soil and soilless container media.

We used the same media and soil described in Wehtje et al., 1993 [1 rice hulls : 1 peat : 1 pine bark :2 wood shavings (R-P-PB-W), 7 pine bark: 1 sand (PB-S), 3 pine bark: 1 peat (PB-P), all ratios are by volume; soil = Marvyn sandy loam, Typic Kanhapludults]. Ringlabeled ${ }^{14} \mathrm{C}$-oryzalin with specific activity of

Received for publication 1 Mar. 1993. Accepted for publication 7 Jan. 1994. Use of trade names does not imply endorsement of the products named nor criticism of similar ones not named. The cost of publishing this paper was defrayed in part by the payment of page charges. Under postal regulations, this paper therefore must be hereby marked advertisement solely to indicate this fact.

'Associate Professor. solution) was greater in media than in soil.

'Professor.
$255 \mathrm{kBq} \cdot \mathrm{mol}^{-1}\left(6.89 \mathrm{mCiŽmg} \bar{g}^{-1}\right)$ was used. The experimental design and statistical treatment were identical to that of Wehtje et al. (1993).

Oryzalin sorption was evaluated in each medium and the soil (Marvyn sandy loam, Typic Kanhapaludults) at 0.01, 0.10, 1.00, 10.0, and 100 mgŽ $\mathrm{kg}^{-1}$ by Wehtje et al.'s (1993) soil solution technique. Through repeated extraction, resorption was examined only for R-P-PB-W and soil, at $10 \mathrm{mg} \bullet \mathrm{kg}^{-1}$. Each extraction removed an average of $71 \mathrm{ml}(42 \%)$ of the $167 \mathrm{ml}$ of water that had been added to R-P-PB-W and $4 \mathrm{ml}(33 \%)$ of the $12 \mathrm{ml}$ that had been added to the soil. Additional water was added to the medium and soil after each extraction to replace the amount lost. Equilibration time between each extraction was $24 \mathrm{~h}$.

Oryzalin mobility was evaluated in each medium and the soil by using a column leaching technique (Wehtje et al., 1993). Oryzalin adsorption by the three media ranged from $93 \%$ to $95 \%$, regardless of oryzalin concentration. At concentrations between 0.01 and 10.0 $m g \check{Z} \mathrm{~kg}^{-1}$, adsorption by the soil and by all media was statistically equivalent. At 100 $\mathrm{mg} \bullet \mathrm{kg}^{-1}$, adsorption by R-P-PB-W and PB-S was greater (both were 94\%) than by soil $(90 \%)$, with a least significant difference of $4 \%$ ( $\mathrm{P} \leq 0.05)$. In contrast to the media, the proportion of oryzalin adsorbed by soil was inversely related to the concentration: $96 \%$ at $0.01 \mathrm{mg} \cdot \mathrm{kg}^{-1}$ and $90 \%$ at $100 \mathrm{mgŽkg}{ }^{-1}$.

Amount of oryzalin removed from R-P-PB-W with each of five consecutive ex- tractions was $7.4 \%, 4.2 \%, 2.6 \%, 2.7 \%$, and $2.8 \%$, resulting in $19.7 \%$ cumulative extraction. The amount recovered decreased by $43 \%$ between the first and second extractions and by $38 \%$ between the second and third. Analogous values with the soil were $8.9 \%, 5.6 \%$, $4.2 \%, 4.0 \%$, and $3.0 \%$ (total $=25.7 \%$ ). The decrease was substantial $(37 \%)$ only between the first and second extractions. Oryzalin absorptivity by the soil and R-P-PB-W were identical based on a simple onetime equilibration and extraction experiment. The medium had a slightly greater resistance to resorption over repeated cycles of rewetting, equilibrating, and extracting than the soil.

The leachability of oryzalin in R-P-PB-W and PB-S was identical (Table 1); almost all the applied oryzalin was retained within $4 \mathrm{~cm}$ of the soil surface, with a minimum of 9170 held in the top $2 \mathrm{~cm}$. Oryzalin was least mobile in PB-P, with $99 \%$ being retained in the top 2 $\mathrm{cm}$. In the soil, less oryzalin was retained in the top $2 \mathrm{~cm}$, and correspondingly, more was held between 3 and $4 \mathrm{~cm}$.

Oryzalin adsorption and resistance to leaching was high in the organic media and soil; for both, adsorption was somewhat reversible. Weed control activity in nursery and landscape situations probably depends on this resorption. Each rewetting of the medium through either irrigation or rainfall results in a portion of the applied oryzalin reentering the soil solution where it can be adsorbed by germinating weed seeds.

These data indicate oryzalin movement in container media is limited and likely would not be displaced out of containers via irrigation run off.

\section{Literature Cited}

Keese, R. J., T. Whitwell, N.D. Camper, and M. Riley. 1992. Oryzalin, penimethalin and oxyfluorfen levels in water and sediment from container nursery ponds. Proc. Southern Weed Sci. Soc. 45:141.

Wehtje, G. R., C.H. Gilliam, and B.F. Hajek. 1993. Adsorption, resorption, and leaching of oxadiazon in container media and soil. HortScience 28:126-128.
Table 1. Relative mobility of oryzalin in soilless media and soil as determined by column leaching.

\begin{tabular}{lcccr}
\hline \hline Distance from & \multicolumn{4}{c}{ Oryzalin (\% recovered) } \\
\cline { 2 - 5 } surface (cm) & R-P-PB-W & PB-S & PB-P & Soil \\
\hline $0-2$ & $92^{y}$ & 91 & 99 & 85 \\
$3-4$ & 8 & 8 & 1 & 11 \\
$5-10$ & $\leq 1$ & $\leq 3$ & $<1$ & $\leq 3$
\end{tabular}

${ }^{2}$ R-P-PB-W = 1 rice hulls: 1 peat: 1 pine bark: 2 wood shavings; $P B-S=7$ pine bark: 1 sand; $P B-P=3$ pine bark :1 peat; all ratios are by volume. Soil= Marvyn sandy loam, Typic Kanhapludults. ${ }^{y} \mathrm{LSD}_{005}$ between any two means $=8.0$. 